\title{
SEVERE COCCIDIOSIS ASSOCIATED TO FETAL DEATH IN GOAT- A CASE REPORT
}

\author{
SILVA, M.A. ${ }^{1}$; DECONTO, I. ${ }^{2}$ FERRARI, M.V. ${ }^{2}$; KOZICKI, L.E. ${ }^{2}$, VILANI, R.C.D. ${ }^{3}$ \\ ${ }^{1}$ FFLM (Fundação Faculdades "Luiz Meneghel"); \\ ${ }^{2}$ Departamento de Medicina Veterinária - UFPR; \\ ${ }^{3}$ PUC-PR (Pontifícia Universidade Católica do Paraná).
}

On May 2000, at the Large Animals Clinics of the UFPR Veterinary Hospital a goat (Capra hircus) of the race Mambrina (weight approximate $30 \mathrm{~kg}$ ), has been assisted. This goat showed profuse, fetid and bloody diarrhea, apathy, caquexia and weakness. At the physical anamenesis, tachycardia was observed (126 beats/minute) width the presence of heart blows, extremely pale ocular mucous membranes, breathing frequency of 40 breaths/minute and body temperature of $39.4^{\circ} \mathrm{C}$. During the exam pregnancy of the patient has been diagnosed. Through abdominal palpation and trans-abdominal ultrasonography it was found out that the fetuses (minimum two) were dead. The clinical pathology revealed severe anemia (PCV 6\% and total count of erythrocytes 1,3 million/(L), presence of acute infection (leukocytosis-50800 leukocytes/(L, neutrophilia-42600 neutrophils/(L, left shift-1010 bands/(L and lymphopenia-6600 lymphocytes/(L) and hypoproteinemia $(4,4 \mathrm{~g} / \mathrm{dL})$. The fecal examination revealed high amount of oocysts (+++) in the feces. The disease was diagnosed as severe coccidiosis with severe anemia worsened by caquexia and fetal death. The treatment was based on the therapy of support of the animal, with administration of vitamins $B$, vitamin $A, D$ and $E$. A blood transfusion (1000 $\mathrm{mL}$ of blood) has been provided to the goat which was followed by a Cesarean operation for the removal of the dead fetuses ( 3 immature fetuses). The lombo-sacra epidural anesthesy was used because of the gravity of the general state of the animal. The treatment of the coccidiosis was constituted by daily administration of sulfadoxine (33 mg.kg-1) associatedwith trimethoprim (6,6 mg.kg-1) for eight days. Two days after the beginning of the treatment the animal did not show more bloody diarrhea and fed usually. The clinical evolution was positive. At the ninth day the goat left the Hospital back to its farm of origin. It has been concluded that the fetal death happened due to the mother's severe anemia, worsenned by the intercurrent coccidiosis. The blood transfusion as well as the the emergency Cesarean operation, associated with the positive reply to the chemotherapy with sulfa, were the fundamental factors for the clinical success in this case.

Key Words: Coccidiosis, fetal death, blood transfusion, sulfadoxine, goat. 